\title{
Demyelination in canine distemper virus infection: a review
}

Received: 10 August 2004 / Accepted: 30 August 2004 / Published online: 12 January 2005

(C) Springer-Verlag 2005

\begin{abstract}
Canine distemper virus (CDV) causes severe immunosuppression and neurological disease in dogs, associated with demyelination, and is a model for multiple sclerosis in man. In the early stage of the infection, demyelination is associated with viral replication in the white matter. In acute demyelinating lesions there is massive down-regulation of myelin transcription and metabolic impairment of the myelin-producing cells, but there is no evidence that these cells are undergoing apoptosis or necrosis. Oligodendroglial change is related to restricted infection of these cells (transcription but no translation) and marked activation of microglial cells in acute lesions. Concomitant with immunological recovery during the further course of the disease, inflammation occurs in the demyelinating plaques with progression of the lesions in some animals. A series of experiments in vitro suggests that chronic inflammatory demyelination is due to a bystander mechanism resulting from interactions between macrophages and antiviral antibodies. Autoimmune reactions are also observed, but do not correlate with the course of the disease. The progressive or relapsing course of the disease is associated with viral persistence in the nervous system. Persistence of CDV in the brain appears to be favored by non-cytolytic selective spread of the virus and restricted infection, in this way escaping immune surveillance in the CNS. The CDV Fusion protein appears to play an important role in CDV persistence. Similarities between canine distemper and rodent models of virus-induced demyelination are discussed.
\end{abstract}

Keywords Canine distemper virus - Nervous system · Pathogenesis · Demyelination · Review

M. Vandevelde $(\bowtie) \cdot$ A. Zurbriggen

Institute of Animal Neurology,

Department of clinical veterinary medicine,

University of Berne, P.O. Box 2735,

3001 Berne, Switzerland

E-mail: marc.vandevelde@itn.unibe.ch

Tel.: + 41-31-6312509

Fax: +41-31-6312538

\section{Introduction}

Epidemiological observations strongly suggest that multiple sclerosis (MS) is a disease caused by an infectious agent that induces an immune-mediated demyelinating disease $[9,54]$. While much progress has been made in recent years, the pathogenesis of MS is still unclear, and animal models of viral demyelination remain important tools in MS research. The fact that the mouse genome has been sequenced and that transgenes can be routinely produced has greatly advanced the use of this species in pathogenesis research. This is also true for infectious diseases including virusinduced demyelination [22, 62]. While none of the rodent models truly resemble MS, a variety of widely diverging mechanisms of virus-induced demyelination have been elaborated in these animals. This diversity is not surprising since infectious diseases are generally the result of co-evolution of infectious agents and their hosts, and their pathogenesis is determined by highly complex interactions. Such interactions involve adaptation of the agent to host cells, specific tropism, neuro-invasiveness, anti-virus immune response, etc. Therefore, it can be hardly expected that an exact replica of MS could be reproduced in a single viral model, and it makes sense to investigate various species-agent combinations, including diseases in larger animals.

A spontaneous MS-like disease with multifocal demyelinating lesions is rare in domestic animals, in which systematic neuropathological screening has been performed for at least half a century in various labs around the world. While such studies focused to a large extent on companion animals, the creation of surveillance systems to control the BSE outbreak in Europe during the past two decades led to the histological examination of hundreds of thousands of ruminant brains, considerably increasing the database on large animal neuropathology. Primary demyelination in domestic animals has only been observed for 
Visna, a lentivirus infection in sheep and in canine distemper virus (CDV) infection. While demyelination is a rare complication in the former, it occurs with very high frequency in distemper. Canine distemper has been recognized as a disease entity for over two hundred years. The first description of demyelination in this disease originates from 1877 by Gowers and Sankey [53]. This canine lesion continued to fascinate human neuropathologists such as H.J. Scherer [55], who quite boldly described it as: "acute multiple sclerosis of the dog".

\section{Canine distemper virus}

Despite widespread use of vaccination, distemper continues to be a problem with outbreaks occurring in canine populations, but also in other species such as seals and lions [8, 31, 49]. CDV is an enveloped, non-segmented, single-stranded RNA virus and is a member of the morbilliviruses, thus closely related to measles virus. CDV possesses a nucleocapsid containing the viral genome, which consists of the nucleoprotein $(\mathrm{N})$ and the polymerase complex including the $\mathrm{P}$ and $\mathrm{L}$ proteins. The membrane protein $(\mathrm{M})$ is located at the inner surface of the envelope, which exhibits two surface glycoproteins : the attachment protein $(\mathrm{H})$ and the fusion protein $(\mathrm{F})$. The cellular receptor for the $\mathrm{H}$ protein in vivo has not been determined. CD9 acts as a receptor for attenuated CDV in cell lines but not for virulent CDV [41]. The signaling lymphocyte activation molecule (SLAM) was shown to be a very efficient receptor for wild CDV [59] in canine SLAM transfected tissue cultures, in which wild CDV can normally only be propagated following repeated passages. However, immunocytochemical studies showed only very limited expression of SLAM in the CNS, as compared to lymphoid tissues (studies in progress). Therefore, it is probable that other viral receptors exist.

CDV in dogs is generally transmitted as an aerosol infection to the upper respiratory tract. Primary virus replication takes place in the lymphoid tissues (Fig. 1A), leading to severe long-lasting immunosuppression [5, 37, 39]. $\mathrm{T}$ cells are more affected than $\mathrm{B}$ cells [35], and $\mathrm{CD} 4^{+}$lymphocytes are rapidly depleted for several weeks [70], probably by virus induced apoptosis [40. 46], whereas CD $8^{+}$cells are less severely affected and recover relatively fast [70]. At about 10 days post infection (p.i.), CDV starts to spread from sites of primary replication to various epithelial tissues (Fig. 1B) and the central nervous system (CNS). As a result of epithelial infection, respiratory, intestinal and dermatological signs can occur. The most serious complication is infection of the CNS, leading to a variety of neurological syndromes, frequently with bad prognosis [68]. Neurological signs often occur in the absence of systemic signs. In the following we present a review of what is known about the neuropathology of CDV infection in its natural host, the dog.

\section{Neuropathology of nervous distemper}

While strain variation and related differences in lesion patterns exist [65], in the vast majority of spontaneous distemper cases and in experimental studies with socalled "demyelinating" strains such as R252 [43] and A75/17 CDV [64], the virus causes multifocal lesions in the gray and white matter of the CNS [67]. Generally, demyelinating lesions prevail, and gray matter lesions may be lacking. The predilection sites are the white matter of the cerebellum, the periventricular white matter, especially around the fourth ventricle, the optic pathways and the spinal cord (Fig. 1B). CDV enters the brain by infected mononuclear cells penetrating the blood barrier but, possibly more importantly, by circulating in the CSF (Fig. 1E) and fusing with the ependymal lining of the ventricles [33]. This explains the frequent periventricular and subpial location of the lesions. In the following sections, we will focus on what is known about the pathogenesis of the white matter lesions in distemper.

Pathogenetic studies have to consider an acute and a chronic stage in the development of CDV-induced demyelination. The initial demyelinating lesions occur around 3 weeks p.i. and evolve during a period of massive virus-induced immunosuppression [72]. Depending on the degree and speed of immune recovery, animals may either become quickly moribund or may recover after developing a mild or even subclinical illness. An intermediate group of animals recovers slowly or partially, and tends to develop a chronic or even relapsing disease $[10,34]$ with progression of the demyelinating lesions as a result of immunopathological reactions $[71,73]$.

\section{The acute stage of distemper: virus-induced demyelination}

Infection of the glial cells of the white matter

The initial myelin lesions develop during a period of severe immunosuppression and are not inflammatory [72] in the traditional sense of the word, since perivascular cuffs are entirely lacking. Initial lesions are characterized by ballooning of myelin sheets with vacuolation of the white matter, myelin phagocytosis and astrocytic swelling (Fig. 2A). Several immunocytochemical studies and in situ hybridization work in spontaneous and experimental distemper have clearly shown that demyelination coincides with replication of CDV in the glial cells (Fig. 1C, D, F) of the white matter $[75,83]$. Spatio-temporal studies leave no doubt that the initial white matter lesions are associated with viral activity and that their development is highly predictable $[32,33,64,75]$. The obvious explanation for the phenomenon of demyelination would be infection of oligodendrocytes. A primary insult to the oligodendrocyte 
Fig. 1 CDV infection. A At 6 days p.i., massive virus replication in thymus is seen; in situ hybridization for CDV $\mathrm{N}$ mRNA. B At 10 days p.i., widespread infection in epidermis is seen; immunestaining for CDV (red), antiCDV N-ABC. C At 21 days p.i. widespread infection is seen in white matter of cerebellum; in situ hybridization for CDV $\mathrm{N}$ mRNA. D Non-cytolytic astrocytic infection is seen in white matter; in situ hybridization for CDV N mRNA. E Infection of choroid plexus, ependyma and subependymal cells around IVth ventricle is seen; in situ hybridization for CDV N mRNA. F Acute demyelination with vacuolation of white matter coinciding with productive infection in glial cells, immunostaining for CDV with anti-CDV-PAP ( $C D V$ canine distemper virus, $p . i$. post infection, $P A P$ peroxidaseantiperoxidase). A, C, E $\times 40 ; \mathbf{B}$ $\times 200 ; \mathbf{D} \times 400 ; \mathbf{F} \times 100$
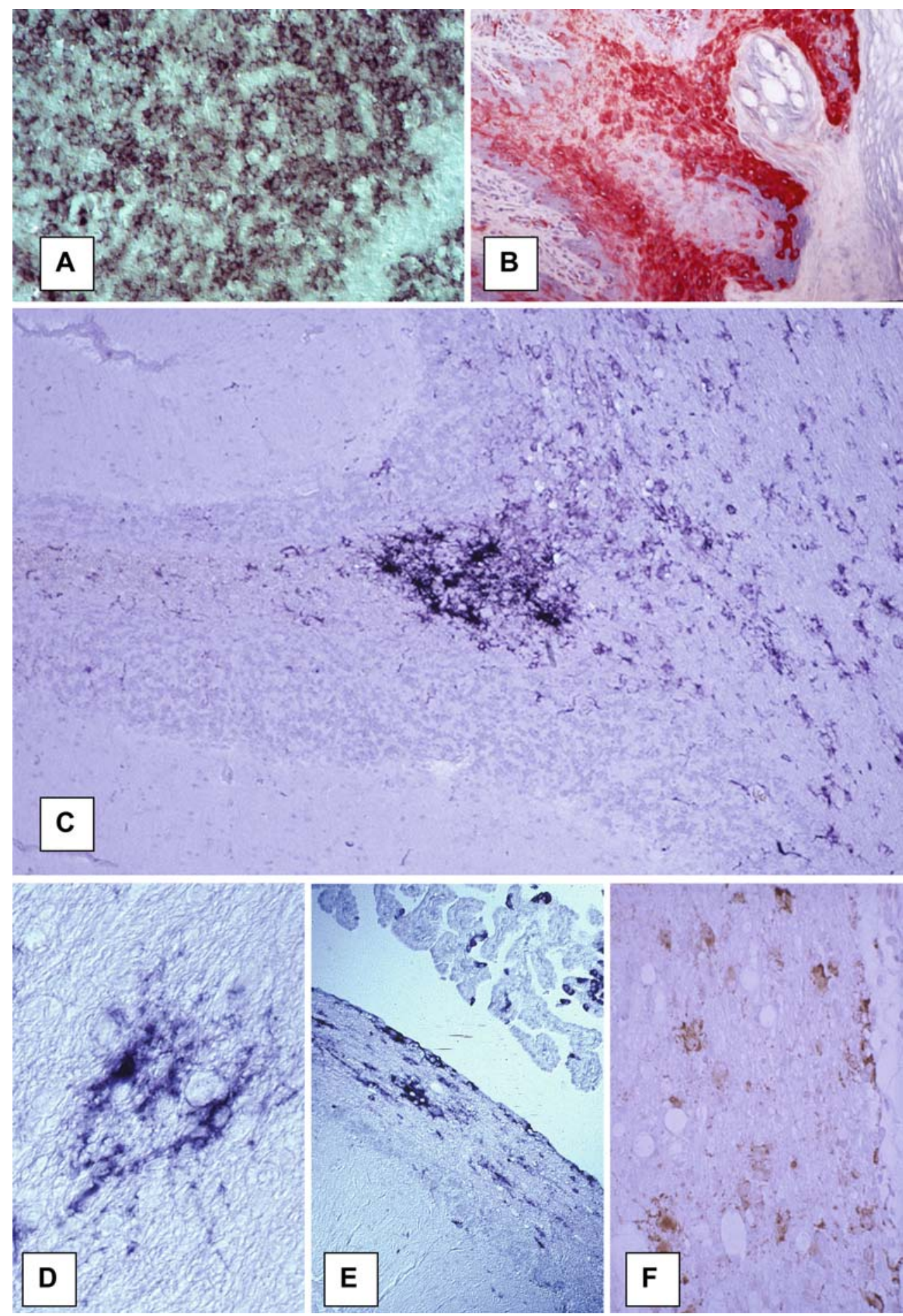

is strongly supported by the finding of segmental demyelination in distemper by Higgins et al. [33]. Therefore, research has focused on finding evidence of CDV in oligodendrocytes. At the light microscopic level, it has been shown that the majority of infected cells in the white matter are astrocytes [48]. Most electron microscopical studies agree that oligodendroglial infection is very rare in distemper [13, 33, 52, 63, 78].
Immunocytochemical staining for CDV combined with in situ hybridization for proteolipid protein (PLP) messenger RNA showed only very few oligodendrocytes containing CDV protein (Fig. 2E). However, approximately $8 \%$ of the oligodendrocytes (Fig. 2F) at the edge of lesions contained CDV mRNA [85]. A restricted infection of oligodendrocytes with viral transcription but no translation (Fig. 4) had been found earlier in dog 


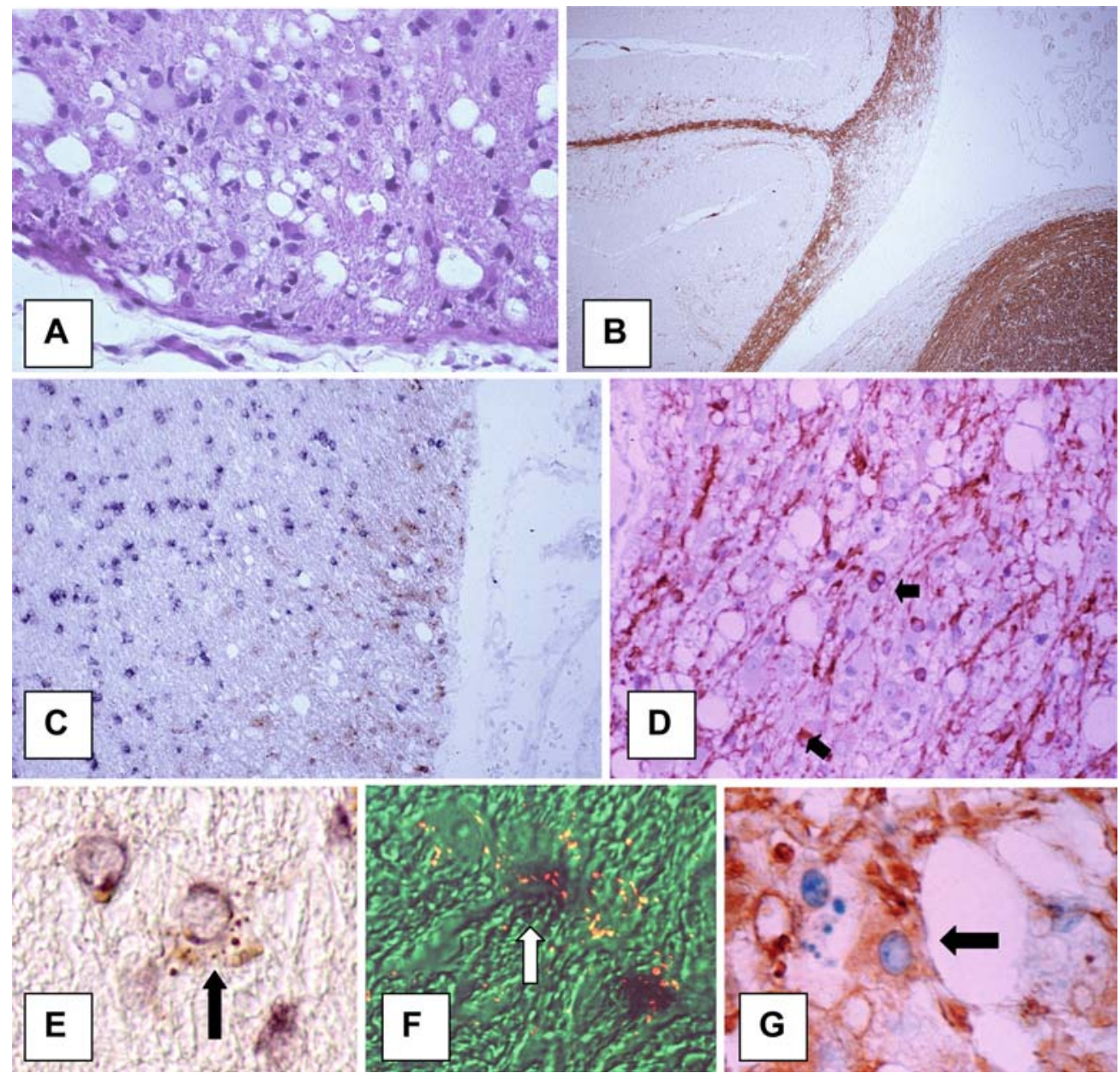

Fig. 2 Acute demyelination in distemper. A At 20 days p.i., acute white matter lesion with vacuolation and astrocytic hypertrophy are seen; hematoxylin and eosin. B At 24 days p.i., a demyelinating plaque in the cerebellum is seen; immunohistological stain antiMBP-PAP. C At 21 days p.i., a demyelinating lesion with marked loss of PLP mRNA staining (blue) of oligodendrocytes; in situ hybridization for PLP m RNA, immunostaining for CDV (brown) with anti-CDV NP-PAP. D At 30 days p.i., advanced lesion with massive loss of myelin is seen. Many oligodendrocytes are still visible in the lesion; immunostaining with anti-CNP-ABC. E Double labeling for CDV (anti-CDV-PAP, brown) and oligodendrocytes (in situ for PLP mRNA, blue). Colocalization of CDV and oligodendrocyte (arrow). F Edge of demyelinating lesion. Double in situ hybridization for PLP mRNA (black) and CDV N mRNA (red), colocalization of virus and oligodendrocytes (arrow). G Hypertrophic oligodendrocyte in demyelinated area, anti-CNPABC $(P L P$ proteolipid protein). A $\times 250 ; \mathbf{B}, \mathbf{C} \times 40 ; \mathbf{F} \times 400 ; \mathbf{G}$ $\times 1,200$

brain cell cultures [83], in which virulent CDV causes a slowly spreading non-cytolytic infection. CDV proteins or viral nucleocapsids were only very rarely found in oligodendrocytes in culture (Fig. 3A, B), in contrast to astrocytes and microglial cells which easily support productive CDV infection [74, 81, 82]. Thus, we concluded from these studies in vivo and in vitro that CDV causes a restricted infection of the oligodendrocytes. Why the production of viral protein does not take place in these cells remains to be clarified.
Changes in oligodendrocytes

Between 20 and 30 days p.i., cultured canine oligodendrocytes, which grow superimposed on a layer of astrocytes in mixed dog brain cell cultures, start to degenerate (Fig. 3C, D), and after several weeks can no longer be detected with immunocytochemical stains for myelin proteins, although the supporting culture remains a continuous cell sheet [82]. Ultrastructural studies revealed microvacuolation and loss of organelles in such oligodendrocytes [23]. These morphological changes are preceded by metabolic dysfunction of these cells: cerebroside-sulfo transferase activity (an oligodendrocyte-specific enzyme) decreased markedly soon after infection [23], and myelin transcription is soon strongly decreased (Fig. 4E) in infected brain cell cultures [24]. In vivo, we could also show that CDV infection led to massive down-regulation of myelin gene transcription with complete loss of in situ hybridization signals for PLP in oligodendrocytes (Fig. 2C) in early demyelinating lesions [85]. Demyelination is apparent before oligodendrocytes disappear in the affected white matter area as seen on immunocytochemical staining (Fig. 2D) for CNPase, an oligodendrocyte-specific enzyme [58]. Some oligodendrocytes appeared to be hypertrophic (Fig. 2G). The fate of the oligodendro- 
Fig. $3 \mathrm{CDV}$ infection in canine brain cell cultures. A Infection of astrocytes; double immunofluorescence labeling with anti-CDV (green) and antiGFAP (red). B Double indirect immunofluorescence labeling with anti-CDV (green) and antiMAG (red) for

oligodendrocytes, no CDV protein in oligodendrocytes. C Normal morphology of oligodendrocytes in uninfected culture, anti-MAG (brown) + anti-O4 (blue)-PAP. D

Degenerating oligodendrocytes in infected culture 25 days p.i., flattening and shortening of cell processes is seen; anti-MAGPAP (GFAP glial fibrillary acidic protein, $M A G$ myelinassociated glycoprotein). A, B $\times 200 ; \mathbf{C}, \mathbf{D} \times 400$
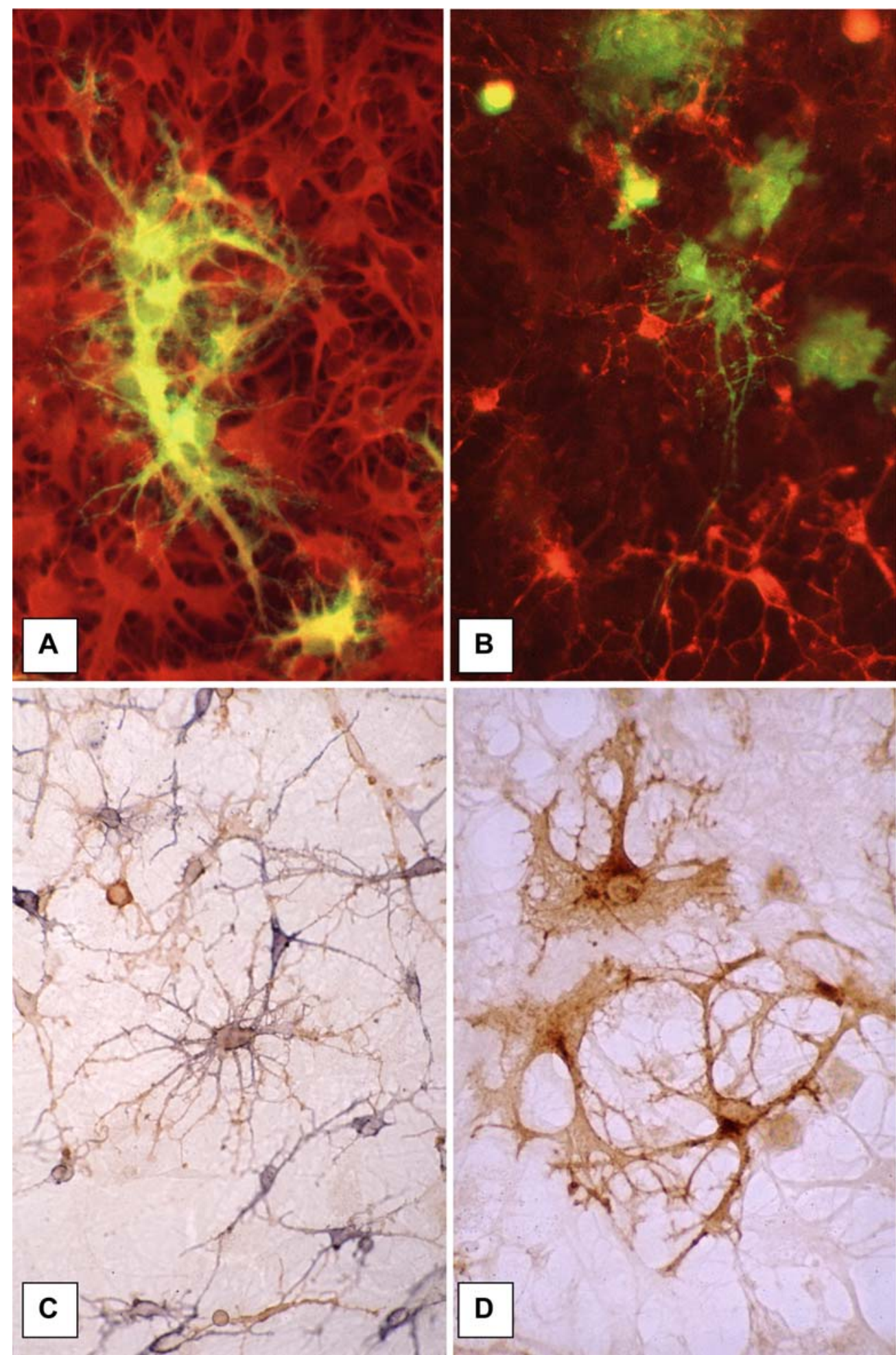

cytes, however, remains unclear. Morphological changes of oligodendrocytes were described in demyelinating lesions in vivo using electron microscopy [13, 63], but there is no concrete evidence that these cells undergo necrosis or apoptosis $[57,58]$. There is little doubt that a change of these cells lies at the base of the demyelinating process but its mechanism is not yet understood. It is possible that viral transcription taking place in these cells interferes with specialized functions necessary to maintain myelin membranes.

In summary, acute CDV infection of the white matter results in metabolic oligodendroglial changes which lead 

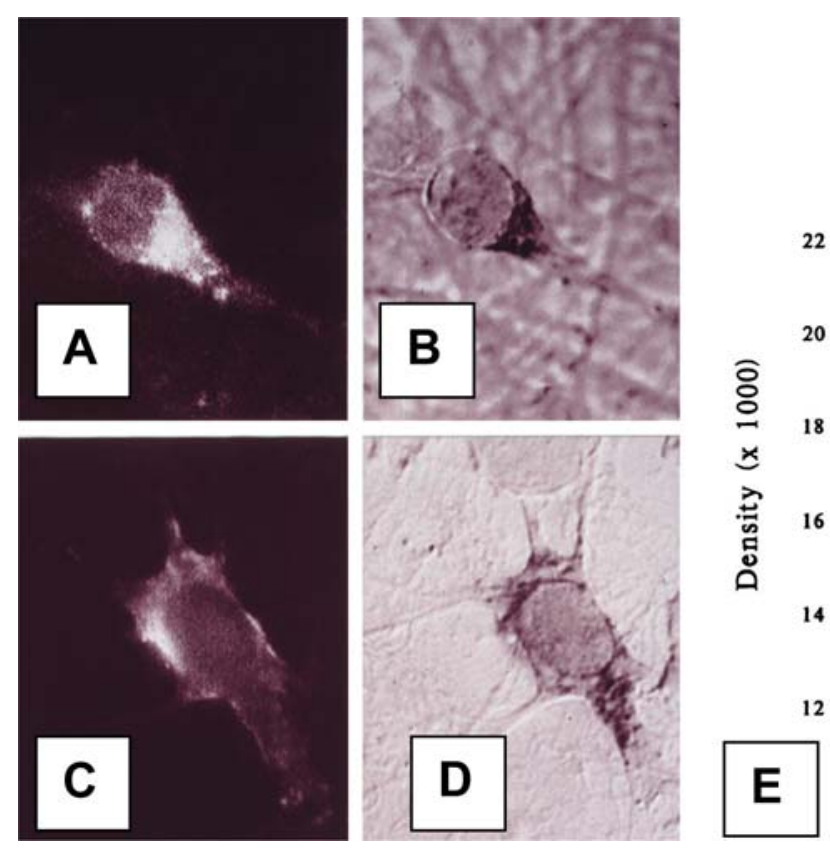

Cellular MBP-mRNA content

Fig. 4 Restricted infection of oligodendrocytes. A-D Immunofluorescence staining for myelin proteins combined with in situ hybridization for CDV m RNA; video microscopy. A Anti-MAGFITC, $\mathbf{B}$ same cell as in A, in situ for CDV N mRNA. C AntiMBP-FITC. D Same cell as in C; in situ for CDV F mRNA. E Densitometric assessment of MBP mRNA in dog brain cell cultures, strong down-regulation of $\mathrm{MBP}$ transcription in CDVinfected cultures ( $M B P$ myelin basic protein). $\mathbf{A}-\mathbf{D} \times 400$

to demyelination. Whether the dysfunction of the oligodendrocyte is the direct result of restricted CDV infection, which has been shown in these cells, remains to be shown. This correlation is apparent in brain cell cultures [24], but since restricted infection in vivo affected less than $10 \%$ of the oligodendrocytes in demyelinating lesions it can not be easily explained why myelin loss in infected white matter areas is nearly complete.

\section{Activation of microglia}

It cannot be excluded that oligodendrocytes are affected as a result of virus-induced changes in other cell types. Alldinger at al. [3] found a diffuse MHC class II up-regulation in the white matter, presumably in the microglial cells, in the early stages of distemper. Activation of microglial cells with release of toxic factors could induce myelin damage. In earlier experiments, we found that supernatants derived from CDV-infected dog brain cell cultures (DBCC) did not induce oligodendroglial lesions in recipient dog or mouse brain cultures [82]. However, extensive treatment of the supernatants to remove infectious virus may have contributed to these negative results. We were also unable to find significant amounts of toxic factors such as TNF- $\alpha$ or reactive oxygen radicals in the supernatants of CDV-infected DBCC [16]. This may have been due to the fact that microglial cells in

mixed brain cell cultures pose only a small fraction of the total cell population. Recently, we developed purified canine microglial cell cultures and found that the activity of ex vivo cultivated microglial cells from dogs with experimentally induced demyelinating distemper exhibited a greatly enhanced expression of MHC and adhesion molecules, phagocytic activity and oxygen radical production. This appeared to be directly related to CDV infection of these cells [60]. These findings are consistent with our previous observations according to which procoagulant activity is enhanced in cultivated CDV-infected macrophages [16]. It is not inappropriate to speculate that CDVinduced microglial cell activation could contribute to oligodendrocyte/myelin damage. This view is supported by experiments in mixed brain cell cultures in which stimulation of microglial cells (Fig. 6A, B) led to considerable damage to the oligodendroglial cells $[15,29]$.

\section{Immune response in early lesions}

In view of the massive virus-induced immunosuppression in distemper soon after infection, we assumed for a long time that humoral and cellular immune responses could hardly play a role in early lesion development. However, several findings cast some doubt on our original view that initial lesions are purely virus induced. While an effective anti-viral neutralizing immune response is indeed completely lacking in the acute phase of distemper, anti-CDV IgM antibodies occur within the first 2 weeks of infection [11]. Despite lack of perivascular cuffing, numerous $\mathrm{CD} 8^{+}$cells are found in acute demyelinating lesions (Fig. 5A-C) and also diffusely distributed in the brain parenchyma, roughly correlating with areas of viral infection [69]. In the CSF of animals 
Fig. 5 Immune-response in the CNS in distemper. A-C Acute demyelinating lesion in anterior medullary velum. A In situ for CDV N mRNA. B Anti-CD18PAP, up-regulation of microglial cells. C Anti-CD3PAP, many diffusely invading $\mathrm{T}$ cells. D At 40 days p.i., inflammatory demyelination around fourth ventricle is seen; myelin stain (Luxol-fast blue). E CDV clearance in inflammatory focus in spinal cord (arrow) and many CDVcontaining cells in surrounding tissue are seen; anti-CDV NPAP. A-C, E $\times 100 ; \mathbf{D} \times 200$

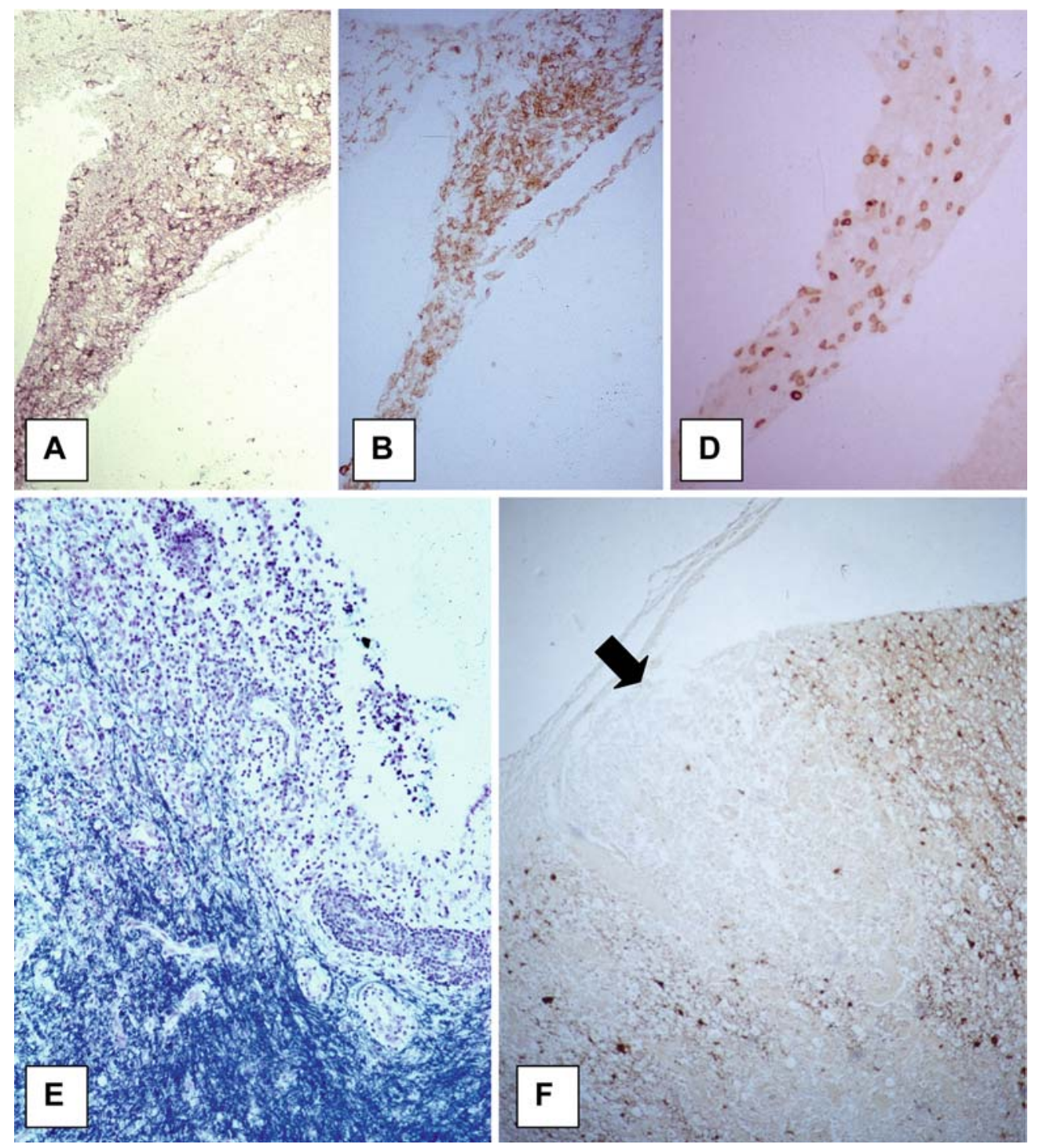

with acute myelin lesions, high IL-8 titers are found [69]. It was suggested that initial microglial cell activation as discussed above may trigger invasion of $\mathrm{T}$ cells in the CNS [69]. Of interest in this respect is that metalloproteinases and their inhibitors appear to be strongly upregulated in acute and subacute lesions in distemper [45]. Systemic antiviral cytotoxic immune reactions have only been shown in the later stage of CDV infection [7]. Invading $\mathrm{T}$ cells in acute lesions do not appear to have an obvious impact on CDV-infected cells since sequential studies showed that the viral load continues to increase until a full inflammatory response develops in the frame of immune recovery [69]. Others have shown that in dogs with demyelinating distemper, pro-inflammatory cytokines are up-regulated, while anti-inflammatory cytokines remain at a base line level [42]. Cytokine upregulation in CNS cells is probably directly virus induced as shown in experimentally infected primary brain cultures [30].

\section{The chronic stage of distemper: inflammatory demyelination}

Coinciding with the recovery of the immune system 6 7 weeks p.i., perivascular cuffing with lymphocytes, plasma cells and monocytes (Fig. 5D) occurs in the initial virus-induced brain lesions [71]. The inflammatory reaction in the demyelinating lesions can lead to progression of tissue damage [73, 78]. There is often frank necrosis of the tissue in such lesions. Thus, the chronic stage of the disease is characterized by immunopathological complications. During immune recovery, a mature immune reaction develops by perivascular infiltration of $\mathrm{CD}^{+}{ }^{+}$cells and subsequent recruitment of large numbers of plasma cells and strong intrathecal antibody synthesis [69, 71, 76, 79]. In inflammatory lesions, pro-inflammatory cytokines are markedly upregulated, whereas anti-inflammatory cytokines remain 
at normal levels [42]. It is possible that astrocytes, a primary target of CDV, participate in the amplification of the immune response. Astrocytes exhibit up-regulated CD44 in their cell membranes in distemper [4] and were shown to loose beta 2 adrenergic receptors [20].

Tissue destruction is related to the antiviral immune response

The titers of CDV neutralizing antibodies in the CSF often exceed those in the serum [14]. Binding studies show that antibodies are made against all proteins of CDV [36]. The occurrence of anti-CDV antibodies in the CSF coincided with clearance of CDV (Fig. 5E) - and CDV-containing cells - from the inflammatory lesions $[2,12,14]$. In chemiluminescence experiments in brain cell cultures, we found that antiviral antibodies, derived from serum and CSF, bound to the surface of CDVinfected cells, interacted with the $\mathrm{Fc}$ receptors of neighboring macrophages, inducing a respiratory burst with release of reactive oxygen radicals [17, 26, 27] (Fig. 6C, D). We also showed that stimulation of macrophages in brain cell cultures in various ways including
Fig. 6 Macrophage stimulation in brain cell cultures. A Oligodendrocytes in normal untreated culture; antigalactocerebroside-FITC. B Oligodendrocytes $48 \mathrm{~h}$ following macrophage stimulation with zymosan, showing marked loss of cell processes; antigalactocerebroside-FITC. C Proximity of microglial cell labeled with opsonized erythrocytes and immunostained (anti-MAGFITC) oligodendrocyte. D Chemiluminescence following treatment of brain cultures with anti-CDV antibodies derived from dogs with distemper, showing marked respiratory burst (open squares: uninfected culture, full squares: CDVinfected culture). A, B $\times 200$; C $\times 400$
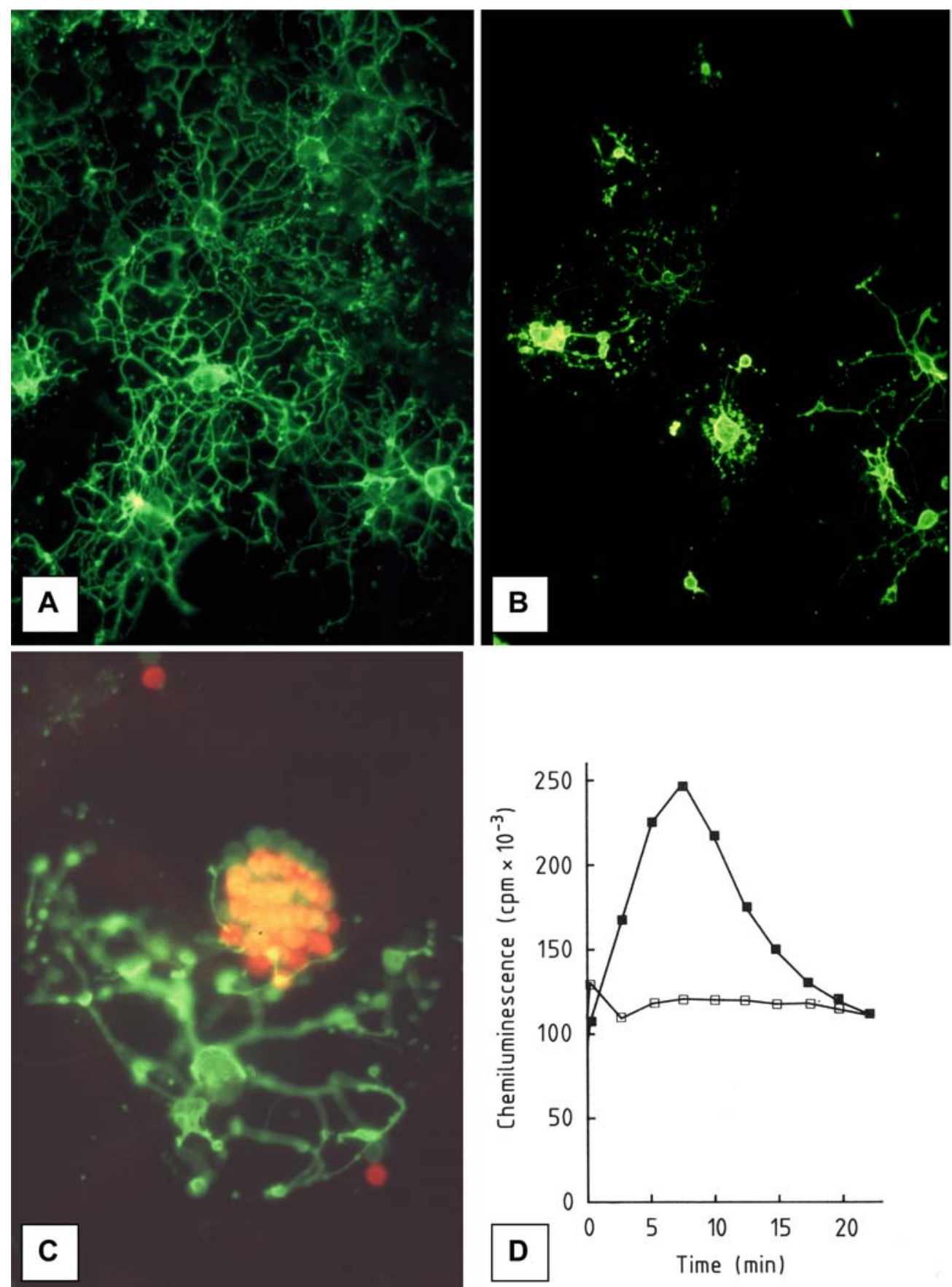
antiviral antibody-virus immune complexes led to selective destruction of oligodendrocytes in their vicinity [15, 29] (Fig. 6A, B). Thus, these experiments showed how the humoral antiviral immune response could lead to destruction of oligodendrocytes as "innocent bystander" cells. Obviously, several products secreted by stimulated macrophages, including reactive oxygen radicals can be made responsible for damage to the oligodendrocyte/myelin compartment. Chemically produced reactive oxygen radicals in the xantine/xantine-oxydase system, which was added to the culture supernatant, selectively damaged cultured oligodendrocytes [28] which are rich in iron compounds [25], rendering these cells particularly vulnerable to oxygen radical attack. The observed marked up-regulation of microglial/macrophage activity in CDV infection [16, 60], as discussed earlier in this paper, may enhance the destructive potential of these cells, and provide further support for the hypothesis that bystander demyelination occurs in chronic distemper. The experimental conditions in the antibody experiments in vitro closely mimic the situation in vivo, in which CDV-infected glial cells in the white matter are in close contact with macrophages and antiviral antibody-producing cells. Therefore, it is not unreasonable to conclude that a bystander mechanism associated with the antiviral immune response can be made responsible for the progression of demyelinating lesions in the chronic stage of CDV infection.

Virus-induced autoimmunity in distemper?

Anti-myelin antibodies in serum have been known for a long time to occur in distemper [38]. We also observed such antibodies in the CSF of dogs with distemper, and found that these antibodies are locally produced in the inflammatory brain lesions [76]. A cell-mediated response against myelin basic protein (MBP) was found in 4 of 11 dogs experimentally infected with CDV [18]. However, neither anti-myelin antibodies nor cell-mediated anti-myelin reactions correlated with the course of the disease. In addition, distemper has no resemblance to EAE in dogs [66].

\section{Further progression of the disease: virus persistence}

The antiviral immune response should be beneficial to the host in that CDV is removed from the tissue [14]. However, our studies also showed that CDV can persist in white matter areas outside of the inflammatory demyelinating lesions [14]. It appears therefore that a chronic progressive disease develops if the intrathecal immune response keeps lagging behind viral replication. Thus, virus persistence is the key to the pathogenesis of the chronic lesion. Persistence of measles virus, which is closely related to CDV, in the CNS of humans appears to be associated with the production of defective viruses [56]. Although a restricted expression of surface proteins in the CNS has been suggested in immunocytochemical studies [2], all viral RNAs and proteins are expressed in the CNS in relative proportions consistent with the particular transcription mode of morbilli viruses [47]. Thus, there is no evidence for defective viruses in CDV infection. Rather, persistence of CDV could be related to restricted infection and non cytolytic spread.

\section{Restricted infection}

As described above, CDV infects oligodendrocytes in vitro and in vivo with transcription of the entire viral genome, but very little translation of viral proteins. Such a restricted infection is also detected in neurons in which viral RNA was readily found in the absence of protein expression [47]. In this way, a viral reservoir is created, escaping immunodetection of CDV. It is conceivable that the virus can be reactivated with establishment of a productive infection, precipitating a new episode of inflammation and demyelination.

\section{Non-cytolytic selective spread}

Another factor favoring persistence is the fact that virulent CDV in vivo and in vitro causes a non-cytolytic infection, limiting the exposure of local immune cells to CDV antigens. To investigate mechanisms of persistence, we have compared several biological and molecular features between the wild persistent virus and an attenuated CDV which does not persist. We found that persistent CDV spreads in primary brain tissue cultures in a non-cytolytic heterogeneous manner with very limited release of infectious virus [84] as compared to attenuated viruses, which spread in a concentric cytolytic pattern through massive release of viral particles (Fig. 7A, B). Both lack of cytolysis and little shedding of virus in the extracellular space in the CNS would appear to limit activation of the local immune response, thus favoring persistence.

Ultrastructurally, persistent CDV was found to produce only few viral buds as compared to non-persistent CDV [44]. The strongly reduced production of viral particles in limited areas of the cell membrane, explains by itself the heterogeneous infection pattern with single infected cells amidst uninfected ones. This pattern is even more pronounced in CNS cells possessing long processes further increasing the spacing between infected cells and rendering the impression that infection is transmitted by way of cell processes (Fig. 7C). The budding process of morbilli viruses is quite complex and requires specific spatial arrangements of the viral proteins at the cell membrane [50]. Confocal microscopical studies revealed a limited colocalization of $\mathrm{F}$ and $\mathrm{H}$ (Fig. 7E, F), both surface proteins of CDV, in the persistent infection as compared to the non-persistent virus where $\mathrm{H}$ and $\mathrm{F}$ were always colocalized [44]. Infection experiments with vaccinia constructs, containing either 
Fig. $7 \mathrm{CDV}$ persistence in vitro. A Non-persistent CDV strain, showing centrifugal compact viral spread with cellcell fusion and cytolysis in center of infected area; antiCDV N-PAP. B Virulent persistent CDV strain, showing heterogeneous infection pattern with single infected cells amidst uninfected ones. Infected cells are not cytolytic and do not fuse; anti-CDV N-PAP. C Persistent CDV, showing viral antigen in cell processes rendering the impression of cell to cell spread; anti-CDV NPAP. D Expression of $F$ protein of A75/17-CDV (persistent strain) and OP-CDV (cytolytic strain); Western blot analysis of cells transfected with empty vector and plasmids containing the $\mathrm{F}$ genes of either strain. The positions of the $\mathrm{F} 0$ and $\mathrm{F} 1$ protein are indicated. In A75/17 CDV, two additional higher molecular weight bands are seen corresponding to the two $\mathrm{F}$ precursor proteins $\left(\mathrm{F}^{*} *\right.$ and F0**). E, F Double

immunofluorescence labeling for $\mathrm{F}(\mathrm{red}, \mathbf{a})$ and $\mathrm{H}$ (green, $\mathbf{b})$ proteins of CDV. E Persistent CDV strain, showing hardly any colocalization of the two proteins (arrows). F Nonpersistent CDV strain, showing clear colocalization of $\mathrm{H}$ and $\mathrm{F}$ (circles). $\mathbf{A} \times 40 ; \mathbf{B} \times 100 ; \mathbf{C} \times 400$; $\mathbf{E}, \mathbf{F} \times 200$
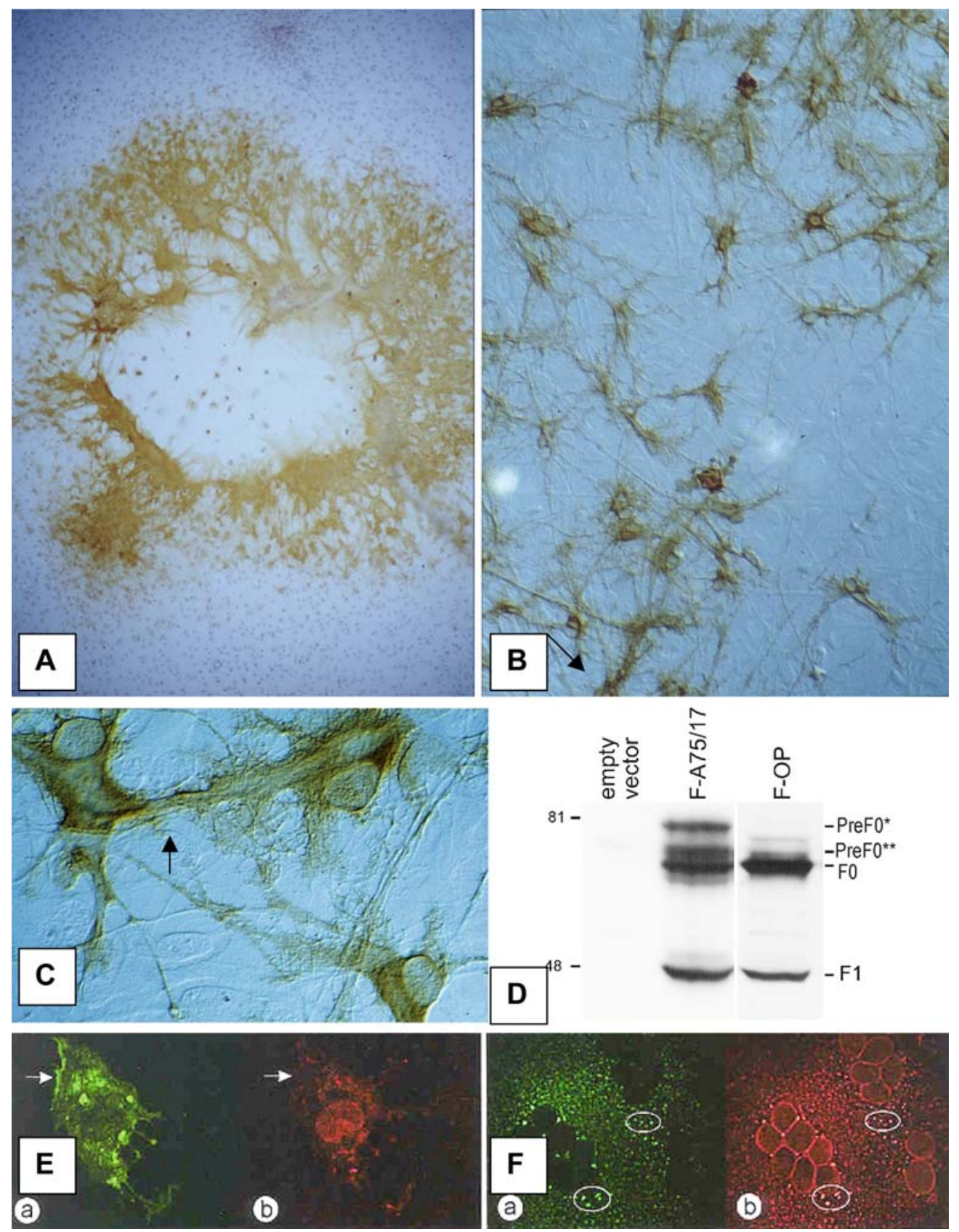

F gene of persistent or non-persistent CDV revealed an additional large fraction of uncleaved $F$ protein in the persistent infection (Fig. 7D), indicating clear differences in intracellular processing of the $\mathrm{F}$ protein between the two CDV strains [44].

In addition to limited release of infectious virus, there is a paucity of cell-cell fusion in the persistent infection, in contrast to the non-persistent virus, which induces large cytolytic syncytia [44]. In measles virus it has been established that cytolysis occurs when a critical number of cells are fused [21]. Thus, lack of cytolysis is related to lack of cell-cell fusion. We concluded from our studies that persistence appears to be related to very limited expression of fusogenic complexes in the cell membrane.
Limited budding and lack of cell-cell fusion may have a common denominator in the configuration and processing of the $\mathrm{F}$ protein.

\section{Molecular determinants of viral persistence}

Since sequencing studies have shown differences between virulent and attenuated CDV at the level of all genes ([19, 61]; Gene bank AF164967), it is hardly feasible to relate persistence to single molecular determinants. In view of the findings described above, attention has been focused on the F protein. The primary transcript of the $F$ protein consists of a precursor protein containing a 
relatively long sequence of amino acids preceding an internal signal peptide allowing the entry of this protein in endoplasmic reticulum [77]. This long sequence called Pre sequence is cleaved between amino acids 135 and 136. Comparing sequences of cytolytic, non-persistent CDV strain with persistent CDV, major differences between the two strains were found in the Pre sequence of the $\mathrm{F}$ protein [19]. F protein hybrids were constructed consisting of various combinations of the Pre sequence and the F0 of both strains. Transfection of cell lines with plasmids containing the attachment protein of the attenuated virus and fusion protein hybrids of either strains showed that the Pre sequence of the cytolytic virus greatly influenced the fusion efficiency of the wildtype F0 and vice versa (studies in progress). Thus, it was concluded that the Pre sequence, perhaps by modifying the cleavage efficiency of the signal peptide, plays an important role in the intracellular processing of the $\mathrm{F}$ protein and the efficiency of expression of fusogenic complexes in the cell membrane. Using reverse genetics, a rescue system for virulent CDV was developed [51]. Infection experiments using recombinant CDV containing various modifications of the $\mathrm{F}$ protein are in progress.

However, not only viral factors but also cellular factors appear to play an important role in the fusion process. Transfection of cell lines with canine SLAM led to greatly enhanced cell-cell fusion activity following infection with the wild virus (work in progress). From all these experiments, it can be concluded that persistence appears to be related to restriction of syncytia formation, hence avoiding cytolysis.

\section{Conclusions}

There are a number of similarities between canine distemper and murine models of virus-induced demyelination such as Theiler's virus and mouse hepatitis virus infection. As in the mouse models, canine distemper is also a systemic infection with subsequent involvement of the nervous system. Both virus-induced oligodendroglial changes as well as inflammatory myelin damage occur in distemper and in the mouse models. While direct viral destruction of oligodendrocytes has been found in mice, there is no clear evidence for oligodendrocyte necrosis or apoptosis in distemper. In distemper there is a restricted infection of oligodendrocytes with a dramatic impairment of myelin metabolism. In addition, virus-induced microglial cell activation probably also plays a role in the demyelinating process. Since extensive experimental manipulation of the immune system as in the murine models is not feasible in dogs, direct comparison between the canine model and the demyelinating conditions in mice is difficult. There is little doubt, however, that the local anti-virus immune/inflammatory response contributes to myelin damage in the sense of a bystander effect in all models, involving a variety of molecules such as reactive oxygen radicals and cytokines. There is evidence for the triggering of autoimmune reactions in some of the mouse models, and also in distemper. It is uncertain to what extent such events play an active role in myelin damage. So far, there is no conclusive evidence in our animal models for a virus-induced autoimmune disease which continues to progress despite complete clearance of the infectious agent, as proposed in MS. Rather, common to distemper and mouse models is virus persistence in the CNS, which appears to be the key to the progression of the disease. Apparently, the persistent agent precipitates recurrent immune reactions even though the infectious load may be very small and difficult to detect. Therefore, a major remaining challenge is to understand mechanisms of virus persistence, which may also lead to new approaches to discover hidden agents in the nervous system.

Acknowledgement This work was supported by the Swiss National Science Foundation (grants 32-49506.96 and 31-56686.99) and the Swiss Multiple Sclerosis Society.

\section{References}

1. Alldinger S, Baumgärtner W, Örvell C (1993) Restricted expression of viral surface proteins in canine distemper encephalitis. Acta Neuropathol 85:635-645

2. Alldinger S, Baumgärtner W, Moll P van, Örvell C (1993) In vivo and in vitro expression of canine distemper viral proteins in dogs and non-domestic carnivores. Arch Virol 132:421-428

3. Alldinger S, Wunschmann A, Baumgärtner W, Voss C, Kremmer E (1996) Up-regulation of major histocompatibility complex class II antigen expression in the central nervous system of dogs with spontaneous canine distemper virus encephalitis. Acta Neuropathol 92:273-280

4. Alldinger S, Fonfara S, Kremmer E, Baumgartner W (2000) Up-regulation of the hyaluronate receptor CD44 in canine distemper demyelinated plaques. Acta Neuropathol 99:138-146

5. Appel MJ (1969) Pathogenesis of canine distemper. Am J Vet Res 30:1167-1182

6. Appel MJ, Glickman LT, Raine CS, Tourtellotte WW (1981) Canine viruses and multiple sclerosis. Neurology 31:944-949

7. Appel MJ, Shek WR, Summers BA (1982) Lymphocyte-mediated immune cytotoxicity in dogs infected with virulent canine distemper virus. Infect Immun 37:592-600

8. Appel MJG, Yates RA, Foley GL (1994) Canine distemper epizootic in lions, tigers and leopards in North America. J Vet Diagn Invest 6:277-288

9. Atkins GJ, McQuaid S, Morris-Downes MM, Galbraith SE, Amor S, Cosby SL, Sheahan BJ (2000) Transient virus infection and multiple sclerosis. Rev Med Virol 10:291-303

10. Axthelm MK, Krakowka S (1998) Experimental old dog encephalitis (ODE) in a gnotobiotic dog Vet Pathol 35:527-534

11. Barben G, Stettler M, Jaggy A, Vandevelde M, Zurbriggen A (1999) Detection of IgM antibodies against the nucleocapsid protein of canine distemper virus in dog sera using a dot-blotassay. Zentralbl Veterinarmed A. 46:115-121

12. Baumgärtner W, Örvell C, Reinacher M (1989) Naturally occurring canine distemper virus encephalitis: distribution and expression of viral polypeptides in nervous tissues. Acta Neuropathol 78:504-512

13. Blakemore WF, Summers BA, Appel MG (1989) Evidence of oligodendrocyte infection and degeneration in canine distemper encephalomyelitis. Acta Neuropathol 77:550-553 
14. Bollo E, Zurbriggen A, Vandevelde M, Fankhauser R (1986) Canine distemper virus clearance in chronic inflammatory demyelination. Acta Neuropathol 72:69-73

15. Botteron C, Zurbriggen A, Griot C, Vandevelde M (1992) Canine distemper virus-immune complexes induce bystander degeneration of oligodendrocytes. Acta Neuropathol 83:402407

16. Brügger M, Jungi TW, Zurbriggen A, Vandevelde M (1992) Canine distemper virus increases procoagulant activity of macrophages. Virology 190:616-623

17. Bürge T, Griot C, Vandevelde M, Peterhans E (1989) Antiviral antibodies stimulate production of reactive oxygen species in cultured canine brain cells infected with canine distemper virus. J Virol 63:2790-2797

18. Cerruti Sola S, Kristensen F, Vandevelde M, Bichsel P, Kihm U (1983) Lymphocyte responsiveness to lectin and myelin antigens in canine distemper infection in relation to the development of demyelinating lesions. J Neuroimmunol 4:77-90

19. Cherpillod P, Beck K, Zurbriggen A, Wittek R (1999) Sequence analysis and expression of the attachment and fusion proteins of canine distemper virus wild-type strain A75/17. J Virol 73:2263-2269

20. De Keyser J, Wilczak N, Walter JH, Zurbriggen A (2001) Disappearance of beta-adrenergic receptors on astrocytes in canine distemper encephalitis: possible implications for the pathogenesis of multiple sclerosis. Neuroreport 12:191-194

21. Duprex WP, McQuaid S, Hangartner L, Billeter MA, Rima BK (1999) Observation of measles virus cell-to-cell spread in astrocytoma cells by using a green fluorescent proteinexpressing recombinant virus. J Virol 73:9568-9575

22. Fazakerley JK, Walker R (2003) Virus demyelination. J Neurovirol 9:148-164

23. Glaus T, Griot C, Richard A, Althaus U, Herschkowitz N, Vandevelde M (1990) Ultrastructural and biochemical findings in brain cell cultures infected with canine distemper virus. Acta Neuropathol 80:59-67

24. Graber H, Müller C, Vandevelde M, Zurbriggen A (1995) Restricted infection with canine distemper virus leads to downregulation of myelin gene transcription in cultured oligodendrocytes. Acta Neuropathol 90:312-318

25. Griot C, Vandevelde M (1988) Transferrin, carbonic anhydrase $\mathrm{C}$ and ferritin in dissociated murine brain cell cultures. J Neuroimmunol 18:333-340

26. Griot C, Bürge T, Vandevelde M, Peterhans E (1989) Antibody-induced generation of reactive oxygen radicals by brain macrophages in canine distemper encephalitis: a mechanism for bystander demyelination. Acta Neuropathol 78:396-403

27. Griot C, Bürge T, Vandevelde M, Peterhans E (1989) Bystander demyelination through antibody induced macrophage activation in canine distemper virus infection. Schweiz Arch Neurol Psychiatr 140:39-41

28. Griot C, Vandevelde M, Richard A, Peterhans E, Stocker R (1990) Selective degeneration of oligodendrocytes mediated by reactive oxygen species. Free Radic Res Commun 11:181-193

29. Griot-Wenk M, Griot C, Pfister H, Vandevelde M (1991) Antibody-dependent cellular cytotoxicity in antimyelin antibody-induced oligodendrocyte damage in vitro. J Neuroimmunol 33:145-155

30. Gröne A, Fonfara S, Baumgartner W (2002) Cell type-dependent cytokine expression after canine distemper virus infection. Viral Immunol 15:493-505

31. Harder TC, Kenter M, Appel MJG, Roelke-Parker ME, Barrett T, Osterhaus ADME (1995) Phylogenetic evidence of canine distemper virus in Serengeti's lions. Vaccine 13:521-523

32. Higgins RJ, Krakowka SG, Metzler A, Koestner A (1982) Primary demyelination in experimental canine distemper virus induced encephalomyelitis in gnotobiotic dogs. Sequential immunologic and morphologic findings. Acta Neuropathol (Berl) 58:1-8

33. Higgins RJ, Krakowka SG, Metzler AE, Koestner A (1982) Experimental canine distemper encephalomyelitis in neonatal gnotobiotic dogs. A sequential ultrastructural study. Acta Neuropathol (Berl) 57:287-295

34. Higgins RJ, Child G, Vandevelde M (1989) Chronic relapsing demyelinating encephalomyelitis associated with persistent spontaneous canine distemper virus infection. Acta Neuropathol 77:441-444

35. Iwatsuki K, Okita M, Ochikubo F, Gemma T, Shin YS, Miyashita N, Mikami T, Kai C (1995) Immunohistochemical analysis of the lymphoid organs of dogs naturally infected with canine distemper virus. J Comp Pathol 113:185-290

36. Johnson GC, Fenner WR, Krakowka S (1988) Production of immunoglobulin $G$ and increased antiviral antibody in cerebrospinal fluid of dogs with delayed-onset canine distemper viral encephalitis. J Neuroimmunol 17:237-251

37. Krakowka S (1982) Mechanisms of in vitro immunosuppression in canine distemper virus infection. J Clin Lab Immunol $8: 187-196$

38. Krakowka S, McCullough B, Koestner A, Olsen R (1973) Myelin-specific autoantibodies associated with central nervous system demyelination in canine distemper virus infection. Infect Immun 8:819-827

39. Krakowka S, Higgins RJ, Koestner A (1980) Canine distemper virus: review of structural and functional modulations in lymphoid tissues. Am J Vet Res 41:284-292

40. Kumagai K, Yamaguchi R, Uchida K, Tateyama S (2004) Lymphoid apoptosis in acute canine distemper. J Vet Med Sci 2004 66:175-181

41. Loffler S, Lottspeich F, Lanza F, Azorsa DO, Meulen V ter, Schneider-Schaulies (1997) CD9, a tetraspan transmembrane protein, renders cells susceptible to canine distemper virus. J Virol 71:42-49

42. Markus S, Failing K, Baumgartner W (2002) Increased expression of pro-inflammatory cytokines and lack of up-regulation of anti-inflammatory cytokines in early distemper CNS lesions. J Neuroimmunol 125:30-41

43. McCullough B, Krakowka S, Koestner A (1974) Experimental canine distemper virus-induced demyelination. Lab Invest 31:216-222

44. Meertens N, Stoffel MH, Cherpillod P, Wittek R, Vandevelde M, Zurbriggen A (2003) Mechanism of reduction of virus release and cell-cell fusion in persistent canine distemper virus infection. Acta Neuropathol 106:303-310

45. Miao Q, Baumgartner W, Failing K, Alldinger S (2003) Phasedependent expression of matrix metalloproteinases and their inhibitors in demyelinating canine distemper encephalitis Acta Neuropathol 106:486-494

46. Moro L, Sousa Martins A de, Moraes Alves C de, Araujo Santos FG de, Santos Nunes JE dos, Carneiro RA, Carvalho $\mathrm{R}$, Vasconcelos AC (2003) Apoptosis in canine distemper. Arch Virol 148:153-164

47. Müller C, Fatzer R, Beck K, Vandevelde M, Zurbriggen A (1995) Studies on canine distemper virus persistence in the nervous system. Acta Neuropathol 89:438-445

48. Mutinelli F, Vandevelde M, Griot C, Richard A (1989) Astrocytic infection in canine distemper virus-induced demyelination. Acta Neuropathol 77:333-335

49. Osterhaus AD, Groen J, De Vries P, Uytdehaag FG, Klingeborn B, Zarnke R (1988) Canine distemper virus in seals. Nature 335:403-404

50. Peeples ME (1991) Paramyxovirus M proteins: pulling it all together and taking it on the road. In: Kingsbury DW (ed) The paramyxoviruses. Plenum Press, New York, pp 427 456

51. Plattet P, Zweifel C, Wiederkehr C, Belloy L, Cherpillod P, Zurbriggen A, Wittek R (2004) Recovery of a persistent canine distemper virus expressing the enhanced green fluorescent protein from cloned cDNA. Virus Res 101:147-153

52. Raine CS (1976) On the development of CNS lesions in natural canine distemper encephalomyelitis. J Neurol Sci 30:13-28

53. Saunders LZ (1973) Some historical aspects of the neuropathology of canine distemper. Schweiz Arch Neurol Psychiatr $112 \cdot 341-352$ 
54. Scarisbrick IA, Rodriguez M (2003) Hit-Hit and hit-Run: viruses in the playing field of multiple sclerosis. Curr Neurol Neurosci Rep 3:265-271

55. Scherer HJ (1944) Vergleichende Pathologie des Nervensystems der Säugetiere. Georg Thieme, Leipzig

56. Schneider-Schaulies J, Niewiesk S, Schneider-Schaulies S, Meulen V ter (1999) Measles virus in the CNS: the role of viral and host factors for the establishment and maintenance of a persistent infection. J Neurovirol 5:613-622

57. Schobesberger M, Zurbriggen A, Summerfield A, Vandevelde M, Griot C (1999) Oligodendroglial degeneration in distemper: apoptosis or necrosis? Acta Neuropathol 97:179-187

58. Schobesberger M, Zurbriggen A, Doherr MG, Weissenbock $H$, Vandevelde M, Lassmann H, Griot C (2002) Demyelination precedes oligodendrocyte loss in canine distemper virus-induced encephalitis. Acta Neuropathol 103:11-19

59. Seki F, Ono N, Yamaguchi R, Yanagi Y (2003) Efficient isolation of wild strains of canine distemper virus in Vero cells expressing canine SLAM (CD150) and their adaptability to marmoset B95a cells. J Virol 77:9943-9950

60. Stein MS, Czub M, Schreiner N, Moore PF, Vandevelde M, Zurbriggen A, Tipold A (2004) Microglial cell activation in demyelinating canine distemper lesions. J Neuroimmunol 153:122-131

61. Stettler M, Beck K, Wagner A, Vandevelde M, Zurbriggen A (1997) Determinants of persistence in canine distemper viruses. Vet Microbiol 57:83-89

62. Stohlman A, Hinton DR (2001) Viral induced demyelination. Brain Pathol 11:92-106

63. Summers BA, Appel MJ (1987) Demyelination in canine distemper encephalomyelitis: an ultrastructural analysis. J Neurocytol 16:871-881

64. Summers BA, Greisen HA, Appel MJ (1979) Early events in canine distemper demyelinating encephalomyelitis. Acta Neuropathol (Berl) 46:1-10

65. Summers BA, Greisen HA, Appel MJ (1984) Canine distemper encephalomyelitis: variation with virus strain. J Comp Pathol 94:65-75

66. Summers BA, Greisen HA, Appel MJ (1984) Canine distemper and experimental allergic encephalomyelitis in the dog: comparative patterns of demyelination. J Comp Pathol 94:575-589

67. Summers BA, Cummings JF, deLahunta A (1995) Veterinary neuropathology. Mosby, St. Louis

68. Tipold A, Jaggy A, Zurbriggen A, Vandevelde M (1996) Neurological signs in canine distemper encephalomyelitis- a clinical study. Eur J Companion Anim Pract 6:33-38

69. Tipold A, Moore P, Zurbriggen A, Burgener I, Barben G, Vandevelde M (1999) Early T-cell response in the central nervous system in canine distemper virus infection. Acta Neuropathol 97:45-56

70. Tipold A, Vandevelde M, Wittek R, Moore P, Summerfield A, Zurbriggen A (2001) Partial protection and intrathecal invasion of CD8 $(+) \mathrm{T}$ cells in acute canine distemper virus infection. Vet Microbiol 83:189-203
71. Vandevelde M, Fankhauser R, Kristensen F, Kristensen B (1981) Immunoglobulins in demyelinating lesions in canine distemper encephalitis. An immunohistological study. Acta Neuropathol 54:31-41

72. Vandevelde M, Higgins RJ, Kristensen B, Kristensen F, Steck AJ, Kihm U (1982) Demyelination in experimental canine distemper virus infection: immunological, pathologic, and immunohistological studies. Acta Neuropathol (Berl) $56: 285-293$

73. Vandevelde M, Kristensen F, Kristensen B, Steck AJ, Kihm U (1982) Immunological and pathological findings in demyelinating encephalitis associated with canine distemper virus infection. Acta Neuropathol (Berl) 56:1-8

74. Vandevelde M, Zurbriggen A, Dumas M, Palmer D (1985) Canine distemper virus does not infect oligodendrocytes in vitro. J Neurol Sci 69:133-137

75. Vandevelde M, Zurbriggen A, Higgins RJ, Palmer D (1985) Spread and distribution of viral antigen in nervous canine distemper. Acta Neuropathol (Berl) 67:211-218

76. Vandevelde M, Zurbriggen A, Steck A, Bichsel P (1986) Studies on the intrathecal humoral immune response in canine distemper encephalitis. J Neuroimmunol 11:41-51

77. Von Messling V, Cattaneo R (2002) Amino-terminal precursor sequence modulates canine distemper virus fusion protein function. J Virol 76:4172-4180

78. Wisniewski H, Raine CS, Kay WJ (1972) Observations on viral demyelinating encephalomyelitis. Canine distemper. Lab Invest 26:589-599

79. Wunschmann A, Alldinger S, Kremmer E, Baumgärtner W (1999) Identification of $\mathrm{CD}^{+}{ }^{+}$and $\mathrm{CD}^{+} \mathrm{T}$ cell subsets and $\mathrm{B}$ cells in the brain of dogs with spontaneous acute, subacute-, and chronic-demyelinating distemper encephalitis. Vet Immunol Immunopathol 67:101-116

80. Wunschmann A, Kremmer E, Baumgartner W (2002) Phenotypical characterization of $\mathrm{T}$ and $\mathrm{B}$ cell areas in lymphoid tissues of dogs with spontaneous distemper. Vet Immunol Immunopathol 73:83-98

81. Zurbriggen A, Vandevelde M, Dumas M (1986) Secondary degeneration of oligodendrocytes in canine distemper virus infection in vitro. Lab Invest 54:424-431

82. Zurbriggen A, Vandevelde M, Dumas M, Griot C, Bollo E (1987) Oligodendroglial pathology in canine distemper virus infection in vitro. Acta Neuropathol (Berl) 74:366-373

83. Zurbriggen A, Yamawaki M, Vandevelde M (1993) Restricted canine distemper virus infection of oligodendrocytes. Lab Invest 68:277-284

84. Zurbriggen A, Graber H, Wagner A, Vandevelde M (1995) Canine distemper persistence in the nervous system is associated with noncytolytic virus spread. J Virol 69:16781686

85. Zurbriggen A, Schmid I, Graber HU, Vandevelde M (1998) Oligodendroglial pathology in canine distemper. Acta Neuropathol 95:71-77 